
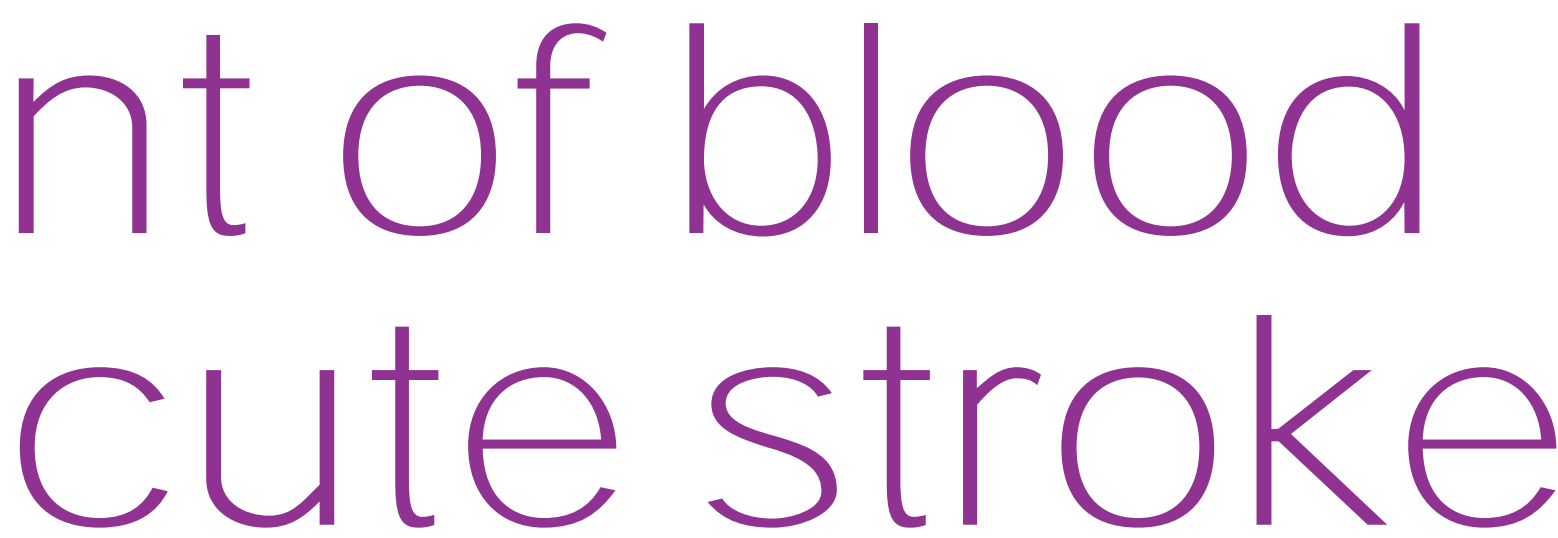

\section{ACUTE STROKE AND HIGH BLOOD PRESSURE}

'High' blood pressure (BP) is defined by the World Health Organization as systolic BP > $140 \mathrm{mmH}$ gand diastolic BP > $90 \mathrm{mmH} \mathrm{g}$. $\mathrm{H}$ igh $\mathrm{BP}$ iscommon in both acuteischaemic and haemorrhagic stroke, affecting about $80 \%$ of the patients, and this reflects several mechanisms (International Society of $\mathrm{H}$ ypertension Writing Group 2003):

- preexisting hypertension;

- thestress of hospitalization;

- raised intracranial pressure(Cushing reflex);

- activation of neuro-endocrine pathways (sympathetic nervous system, mineralocorticoid and glucocorticoid).

TheBP normally falls over the first week after stroke but it can fluctuate considerably making it difficult to discern trends in individuals. The relationship between BP and outcome is ' $U$ shaped' with both high and low BP being associated independently with death or dependency (Fig. 1) (Leonardi-Beeet al. 2002). Thislink be tween high BP and a poor outcomeappearsto be related to an increased risk of early recurrence and fatal cerebral oedema, but not haemorrhagic transformation of the infarct (Leonardi-Bee et al. 2002).

Extrapolating primary and secondary prevention data showing that long-term BP lowering reducestherisk of recurrentstroke(Collins et al. 1990; Rashid et al. 2003a), it seems logical to lower BP during theacutephase of ischaemic strokewith theaim of reducing therisk of early recurrence, and also perhaps of improving outcome by reducing cerebral oedema. Also, in acute primary intracerebral haemorrhage, lowering the BP might reduce the risk of haematoma expansion and re-bleeding. However, cerebral auto-regulation is dysfunctional following acutestroke leading to fears that reducing BP would reducecerebral blood flow (CBF) and so tissue perfusion, especially in patients

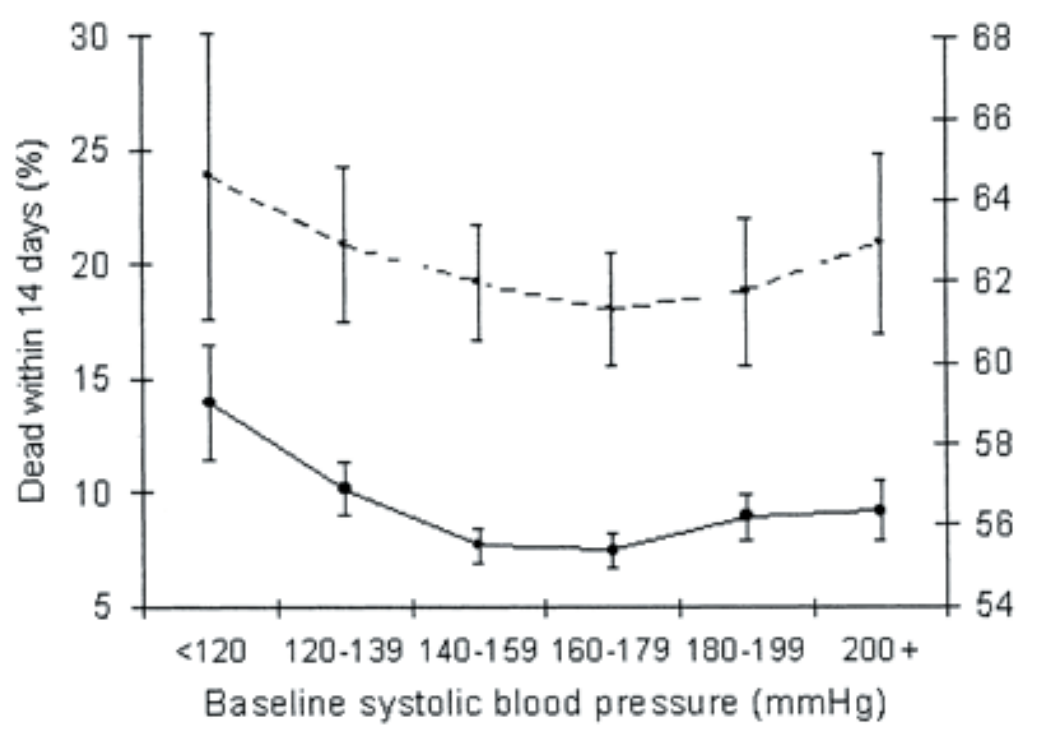

$\rightarrow$ death $\cdots$ death or dependency

Figure 1 Relationship between blood pressure and outcome in acute stroke. Proportion of patients who died within 14 days (solid lines) or were dead or dependent at 6 months (dashed lines) by baseline systolic blood pressure within each blood pressure subgroup; $95 \%$ confidence intervals represented by error bars (Leonardi-Bee et al. 2002). 
with chronic hypertension whose limits of auto-regulation are shifted to the right. Further, if the BP were lowered in patients with very stenotic or occluded carotid arteries, or an inadequate collateral blood supply, this might further compromise cerebral perfusion (Rothwell et al. 2003).

This balance between potential benefit and harm of lowering the BP in acute strokehas yet to beanswered in largetrials (Bath \& Bath 1997; International Society of Hypertension Writing Group 2003; Robinson \& Potter 2004). Unsurprisingly therefore clinical practice varies considerably (Bath et al. 2000). Furthermore, about $60 \%$ of patients with acute stroke al ready have pre-existing hypertension and most are taking anti-hypertensive drugs (International Society of Hypertension Writing Group 2003); whether these patients should continue or temporarily discontinue their prior anti-hypertensive medication remains unclear. Again, in view of the lack of evidence, clinical practicevaries (Lindley et al. 1997; Bath et al. 2000).

\section{TRIALS OF ALTERING BLOOD PRESSURE}

\section{Calcium channel blockers}

M ost data on al tering BP in acute stroke come from randomised trials which tested calcium channel blockers, usually given as potential neuroprotective agents rather than for their effects on BP. A Cochrane meta analysis of 29 trials including 7665 patients showed no benefit with calcium channel blockers, in fact there was a non-significant increase in death and disability (Horn et al. 2001). The Blood Pressurein AcuteStroke Collaboration (2001) also found a trend towards a poor outcome in a review of 11 trials of patients taking oral calcium channel blockers. N either can parenteral administration be recommended (International Society of Hypertension Writing Group 2003); the IN WEST trial of intravenous nimodipine found more neurological deterioration in parallel with effects on diastolic BP (A hmed et al. 2000). In fact, calcium channel blockers have multiple actions in addition to their vasodepressing effects and some may be harmful: in particular, they may reduce regional CBF and induce 'steal' away from the area of infarction.

\section{$\beta$-receptor antagonis ts}

$\beta$-receptor antagonists should theoretically reduce the metabolic demand of ischaemic brain tissue, as well as reduce the BP. H owever, in a randomised trial RCT of atenolol and propranolol in 302 acute stroke patients, there was a trend towards increased early death and poor functional outcome(Barer et al. 1988). $\beta$-receptor antagonists have negative inotropic activity so they may have reduced global CBF.

\section{Labetalol}

Labetalol is a combined alpha and $\beta$-receptor antagonist with some inhibitory effect on al pha-receptors. It was used as part of the protocol for managing hypertension in the $\mathrm{Na}$ tional Institutes of Neurological Disordersand Stroke (NINDS) trial of intravenous thrombolysis in acute ischaemic stroke. Although associated with a reduction in death, this BP lowering was a non-randomised comparison and therefore the data are difficult to interpret (Brott et al. 1998).

\section{Nitric oxide donors}

Nitric oxide donors are neuroprotective, and lower BP, whilst maintaining CBF in experimental stroke(Willmotet al. 2003). In two small trials, transdermal glyceryl trinitrate (GTN) reduced BP without altering platelet activity or middlecerebral artery blood flow velocity (Bath et al. 2001; Rashid et al. 2003b). A recent trial found that GTN reduced systolic BP by $14 \%$ and diastolic BP by $4 \%$ without reducing global, hemispheric or regional CBF; furthermore, GTN did not cause 'cerebral steal'. (Willmot \& Bath, unpublished data).

\section{Angiotens in modifying drugs}

Angiotensin modifying drugs reduce the activity of the renin-angiotensin system and increase CBF at low perfusion pressures by shifting the lower limit of cerebral auto regulation to the left. In a small trial of perindopril, an angiotensin converting enzyme (ACE) inhibitor, there were significant reductions in systemic BP without adverse effects on global CBF or middle cerebral artery blood flow velocity (Dyker et al. 1997). Similar results were seen with losartan, an angiotensin receptor antagonist (ARA) (Nazir et al. 2003). In the ACCESS trial of candesartan, another ARA, there was a significant reduction in the composite outcome of death, cerebral and cardiovascular events (Schrader et al. 2003). H owever, this trial is difficult to interpret because the reduction in morbidity or mortality did not occur 
Table 1 Possible indications for lowering blood pressure acutely in acute stroke
$\mathrm{BP}>220 / 120$
BP > 200/100 with end-organ involvement
- Aortic dissection
- Hypertensive encephalopathy
- Cardiac ischaemia
- Pulmonary oedema
- Acute renal failure

$\mathrm{BP}>200 / 120$ and intracerebral haemorrhage

until well after the 7-day period of treatment, there was no difference in BP between active and control groups, and the trial was stopped early.

\section{Other blood pressure lowering agents}

Not all blood pressure lowering agents lower $\mathrm{BP}$ in the time frame of acute or subacute stroke; for example, the thiazide diuretic, bendrofluazide, failed to reduce BP over one week in a small trial $(n=36)$ (Eames et al. 2004). Centrally acting drugs such as alpha-methyldopa and moxonidine have not been assessed in acute stroke.

\section{URRENT PRACTICE}

In the absence of any proven benefit for lowering $B P$, current guidelines recommend that $B P$ should not be actively lowered in acute stroke. Exceptions to this rule (Table 1 ) include hypertensive patients with severe concomitant vascular complications, e.g. those with aortic dissection, encephalopathy, cardiac ischaemia or failure, and acuterenal failure. Patients with primary intracerebral haemorrhage and high $\mathrm{BP}$ are theoretically at higher risk of haematoma expansion and rebleeding than those with lower BP - some guidelines recommend that they too should have their BP lowered (Adams et al. 2003; International Society of Hypertension Writing Group 2003; Robinson \& Potter 2004).

When treatment for hypertension is indicated the choice of agent is important, and the rate of BP lowering should be cautious. Reduction should probably be in a proportional manner, relative to the baseline blood pressure, rather than target driven (International Society of Hypertension Writing Group 2003). Possible treatment regimes, not yet supported by randomized trials, aregiven in Table 2. Somegeneral tips are:

- Parenteral agents have the advantage that they can betitrated carefully to ensure gradual $\mathrm{BP}$ reduction, although this does require close haemodynamic monitoring in a high dependency environment.

- Although there are no definitive data to support their use, both labetalol and nitrates (sodium nitroprusside or glyceryl trinitrate) have been recommended. But, importantly, sodium nitroprusside has antiplatelet properties (Butterworth et al. 1998) and should probably be avoided in intracranial haemorrhage.

- Sublingual agents such as calcium antagonists and ACE inhibitors should be avoided becausethey haverapid absorption and onset of action which may lead to fast and precipitousfalls in BP.

Table 2 Possible agents for managing hypertension in acute stroke

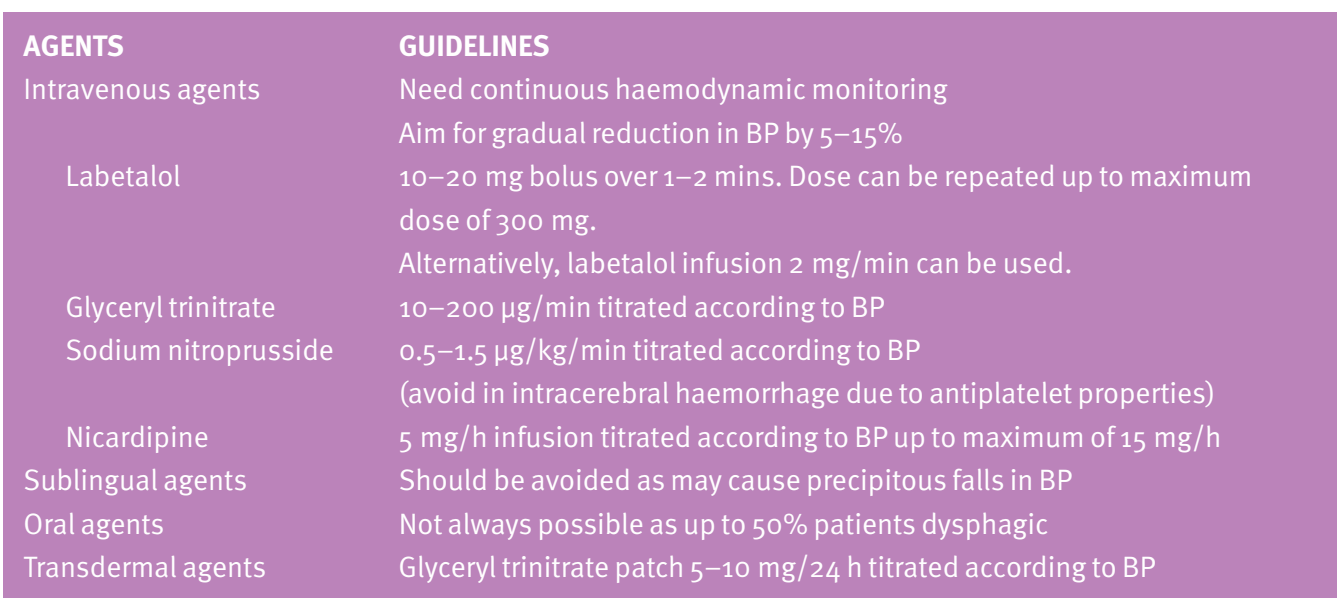




\section{Transdermal preparations have the advantage}

of a relatively slow onset of action and they are

titratable.

- Oral treatments are not always possibleas up to $50 \%$ of patients have dysphagia in acute stroke.

- Transdermal preparations have the advantage of a relatively slow onset of action and they aretitratable; patchescan be removed or additional patches added, in response to BP change.

\section{AC UTE STROKE AND LOW BLOOD PRESSURE}

Low blood pressure is not common in acute stroke but it is, like high BP, associated with a poor outcome (Leonardi-Bee et al. 2002). Reasons for low BP include potentially reversible conditions such as hypovolaemia, sepsis, impaired cardiac output secondary to cardiac failure, arrhythmias or cardiac ischaemia, and aortic dissection. Where present, these conditions need early detection and rapid management with fluid replacement, anti-arrhythmic drugs and inotropic support, as appropriate. Theoretically, raising the BP in hypotensive patients with acute ischaemic stroke might increase perfusion to the ischaemic penumbra. But, aside from vasospasm following subarachnoid haemorrhage, where drug-induced hypertension is standard clinical practice (in combination with hypervolaemia), there are no trial data for treating hypotension in ischaemic stroke. Sympathomimetic vasopressors (e.g. phenylephrine) areused to raiseBP in other fiel ds of acute medicine, but have potential safety drawbacks in acute stroke, including cardiac ischaemia and activating platelet function. Trial data are therefore required before vasopressor therapy can berecommended routinely in hypotensive patients with acute stroke.

\section{ONGOING TRIALS}

To date all studies on BP in acute stroke have been either too small or observational rather than randomised. Data from large randomised trials are urgently needed, as they have been for decades, to provide evidence-based guidelines for the management of hypertension, hypotension and for those on prior anti-hypertensive therapy in acute stroke. A number of ongoing trials are set to address these important questions:

- The Efficacy of Nitric Oxide in Stroke (ENOS) trial is a prospective multicentre randomised trial to assess the safety and efficacy of lowering BP with 1 week of daily transdermal glyceryl trinitrate. Patients re-

CONCLUSIONS

- High blood pressure is a common problem in acute stroke and is associated with an adverse outcome

- Pre-existing hypertension is also common in stroke patients, many of whom are taking antihypertensivetherapy.

- In general, high blood pressureshould not belowered acutely unlessthereisevidence of acute end-organ damage.

- When blood pressure does need to belowered acutely, a cautious proportional approach is recommended with parenteral or transdermal treatment.

- ACE inhibitors, angiotension receptor antagonists and nitric oxide donors are each effective at lowering blood pressure in acute strokealthough their effect on outcome is unknown.

- Therearesafety concerns surrounding theuse of $\beta$-receptor antagonistsand calcium channel blockers in acutestroke

- Low blood pressure in acute stroke is also associated with poor outcome; detection and correction of any reversible cause should bea priority. 
ceiving prior anti-hypertensive agents will also be randomised to temporarily continue or stop. Thetrial will assessthe effect of these interventions in 5000 patients with acute $(<48 \mathrm{~h})$ ischaemic or haemorrhagic stroke at 3 months (http://www.enos.ac.uk). (Bath 2001)

- The Continue Or Stop post Stroke Antihypertensives Collaborative Study (COSSACS) is a multicentrerandomised open trial assessing whether prior anti-hypertensive agents should be stopped or continued in both ischaemic and haemorrhagic stroke patients within $24 \mathrm{~h}$ of onset. The primary outcome is death or dependency assessed at 14 days; 2900 patients will be enrolled (cossacs@le. ac.uk).

- TheScandinavian Candesartan AcuteStroke Trial (SCAST) isfollowing up theinteresting findings of ACCESS by randomizing 2500 patients with acute ischaemic or haemorrhagic stroke $(<30 \mathrm{~h})$ to candesartan or placebo.

- The Controlling Hypertension and Hypotension Immediately Post Stroke (CH HIPS) study will assess pressor therapy (phenylephrine) in hypotensive ischaemic stroke, and depressor therapy (labetalol or lisinopril) in hypertensive ischaemic and haemorrhagic stroke(chips@le.ac.uk).

\section{REFERENCES}

Adams HP, Adams RJ et al. (2003) Guidelines for the early management of patients with ischemic stroke. A scientific statement from the Stroke Council of the American StrokeAssociation. Stroke, 34, 1056- 83.

Ahmed N, Nasman P et al. (2000) Effect of intravenous nimodipine on blood pressure and outcome after acutestroke. Stroke, 31, 1250-5.

Barer DH , Cruickshank JM et al. (1988) Low dose beta blockade in acutestroke('BEST' trial): an evaluation. British M edical Journal, 296, 737-41.

Bath PM (2001) M ajor ongoing stroketrials. Efficacy of Nitric Oxidein Stroke(EN OS) trial. Stroke, 32, 2450- 1 (Abstract).

Bath FJ \& Bath PM W (1997) What is the correct management of blood pressure in acute stroke?TheBlood pressurein AcuteStrokeCollaboration. Cerebrovascular Diseases, 7, 205-13.

Bath PMW, Pathansali R et al. (2001) The effect of transdermal glyceryl trinitrate, a nitric oxide donor, on blood pressure and platelet function in acute stroke. Cerebrovascular Diseases, 11, 265-72.

Bath PM W, Weaver C et al. (2000) A trial of blood pressure reduction in acute stroke. Age Ageing, $\mathbf{2 9}$ 554-5.

Blood pressure in Acute Stroke Collaboration (2001)
The Effect of Vasoactive Drugs on Blood Pressure and O utcome in Acute Stroke (Cochrane Review). Oxford, Update Software.

Brott T, Lu M et al. (1998) Hypertension and its treatment in the NINDS rt-PA stroke trial. Stroke, $\mathbf{2 9}$, 1504-9.

Butterworth RJ,CluckieA et al. (1998) Pathophysiological assessment of nitric oxide (given as sodium nitroprusside) in acute ischaemic stroke. Cerebrovascular Diseases, 8, 158-65.

Collins R, Peto R et al. (1990) Blood-pressure, stroke, and coronary heart-disease.2. short- term reductions in blood-pressure - overview of randomized drug trials in their epidemiologic context. Lancet, 335, 827-38.

Dyker AG, Grosset DG et al. (1997) Perindopril reduces blood pressure but not cerebral blood flow in patients with recent cerebral ischemic stroke. Stroke, $\mathbf{2 8}$ 580-3.

Eames PJ, Robinson TG et al. (2004) The systemic haemodynamic and cerebral auto regulatory effects of bendrofluazidein thesub acutepost-strokeperiod. Journal of Hypertension, 22 2017-24.

Horn J, Limburg L et al. (2001) Cal cium antagonists for acute ischemic stroke (Cochrane Review). The Cochrane Library. Oxford, U pdate Software.

International Society of Hypertension Writing Group (2003) International Society of Hypertension (ISH): statement on the management of blood pressure in acutestroke. Journal of Hypertension, 21, 665-72.

Leonardi-Bee J, Bath PM W et al. (2002) Blood pressure and clinical outcomes in the International Stroke Trial. Stroke, 33, 1315-20.

Lindley RI, Amayo EO et al. (1997) Acute stroke treatment in UK hospitals: the Stroke Association survey of consultant opinion. Journal of the Royal College of Physicians of London, 29, 479-84.

Nazir FS, O verell JR et al. (2003) Theeffect of losartan on global and focal cerebral perfusion and renal function in hypertensives in early ischaemic stroke. Cerebrovascular Diseases, 16, 31 (Abstract).

Rashid P, Leonardi-Bee J et al. (2003a) Blood pressure reduction and thesecondary prevention of strokeand other vascular events: a systematic review. Stroke, $\mathbf{3 4}$ 2741-9.

Rashid P, Weaver C et al. (2003b) The effects of transdermal glyceryl trinitrate, a nitric oxide donor on blood pressure, cerebral and cardiac haemodynamics and plasma nitric oxide levelsin acutestroke.J StrokeCerebrovasc Dis, 13, 143- 51.

Robinson TG \& Potter JF (2004) Blood pressure in acute stroke. Age and Ageing, 33, 6-12.

Rothwell PM , H oward SC et al. (2003) Relationship between blood pressureand stroke risk in patients with symptomatic carotid occlusive disease. Stroke, $\mathbf{3 4}$ 2583-92.

Schrader J, Luders S et al. (2003) The ACCESS Study. Evaluation of acute candesartan therapy in stroke survivors. Stroke, 34, 1699-703.

Willmot M , Murphy Set al. (2003) Systematic review of nitric oxide donors and 1-arginine in experimental stroke: effects on infarct sizeand cerebral blood flow. Cerebrovascular Diseases, 16, 66 (Abstract). 